\title{
MOVIMENTO ENTRE ABSTRATO E CONCRETO NA PROPOSIÇÃO DAVYDOVIANA PARA O ENSINO DE MULTIPLICAÇÃO
}

\author{
JoséLIA EUZÉBIO DA Rosa \\ Universidade do Sul de Santa Catarina (UNISUL), Tubarão, Santa \\ Catarina, Brasil \\ Ediséla Suethe Faust Hobold \\ Universidade do Sul de Santa Catarina (UNISUL), Tubarão, Santa \\ Catarina, Brasil
}

Resumo: A investigação, de natureza bibliográfica, foi desenvolvida no contexto da Educação Matemática, com base nos pressupostos da Teoria Histórico-Cultural. O foco é para a obra de Davýdov. Esse autor pensou a objetivação dos fundamentos da mencionada teoria no ensino e formulou a Teoria do Ensino Desenvolvimental. Tal proposição foi publicada em artigos e livros, e também sistematizada por meio de livros didáticos, manuais de orientação ao professor e relatos de experiência. No presente artigo analisamos a proposição davydoviana para o ensino do conceito de multiplicação. Os resultados indicam que a referida proposição contempla a inter-relação das significações aritméticas, algébricas e geométricas por meio de microciclos orientados em um movimento conceitual de redução do concreto ao abstrato e de ascensão do abstrato ao concreto.

Palavras-Chave: Teoria do Ensino Desenvolvimental. Davýdov. Educação Matemática Escolar. Multiplicação.

movimento ascendente do abstrato para o concreto [...] "é uma lei universal do desenvolvimento do conhecimento humano" (KOPNIN, 1958, p. 317, tradução nossa) ${ }^{1}$. 
A finalidade da educação, com base nos princípios da Teoria Histórico-Cultural, é o desenvolvimento integral do sujeito em vários aspectos, tais como social, cultural, ético, estético, político entre outros. Em relação à educação escolar, segundo Rubinstein (1979, p. 75, tradução nossa), sua finalidade "consiste, sobretudo, em conseguir que o aluno opere facilmente com generalizações já dadas ou firmemente assimiladas". Para tanto, de acordo com Davýdov (1982), é necessário o desenvolvimento do pensamento teórico.

Na educação escolar, a"[...] realização de atividades intencionalmente preparadas para um determinado fim desenvolve, no sujeito, capacidades distintas das efetuadas pela sua inserção espontânea na prática social diária" (WIGGERS, 2014, p. 107). Porém, o acesso à educação escolar não é garantia de desenvolvimento do pensamento teórico, pois depende da lógica que fundamenta o conteúdo e os métodos de ensino. O modo de organização do ensino e a lógica considerada no desenvolvimento dos conceitos interferem no tipo de pensamento que os estudantes desenvolvem: empírico ou teórico (DAVÝDOV, 1982).

Vários problemas que muitos professores encontram no processo de ensino e aprendizagem da Matemática são decorrentes da falta de compreensão e apropriação teórica de conceitos essenciais, como adição, subtração, multiplicação, tabuada, resolução de problemas, divisão, equações, entre outros. Inúmeros estudantes apenas memorizam os processos de resolução de algoritmos de forma mecânica (SILVEIRA, 2015; HOBOLD, 2014; MADEIRA, 2012; NÜRNBERG, 2008; DAMAZIO, 2000; ROSA, 2012), e as dificuldades intensificam-se na medida em que os alunos avançam os anos letivos escolares.

Em várias proposições de ensino, no Brasil, a elaboração dos conceitos é proposta a partir da percepção das características externas de determinado grupo de objetos. Por decorrência desse ponto de partida, sugere-se a abstração da característica essencial, fundamental, comum a todos os objetos. Ao designar os indícios comuns por meio de palavras, atinge-se o conceito em sua dimensão empírica (HOBOLD, 2014). Esse método tem a principal finalidade de"inculcar nas crianças generalizações e conceitos [...] 
empíricos" (DAVÝDOV, 1982, p. 14). Para o autor em referência, muitos livros didáticos são elaborados de forma que objetivam essa finalidade. Neles, as características da abstração, generalização e do conceito coincidem com a descrição da lógica formal tradicional (DAVÝDOV, 1998). A constatação davydoviana é válida para a maioria das proposições brasileiras atuais (ROSA, 2012; HOBOLD, 2014).

A fim de superar o modo de organização do ensino que desenvolve o pensamento empírico, Davýdov elaborou uma proposta de ensino com vistas ao desenvolvimento do pensamento teórico (DAVÍDOV, 1988).

Partimos do pressuposto que tal proposição pode contribuir para a Educação Matemática brasileira. Por isso, neste artigo, apresentamos uma reflexão sobre os fundamentos teórico-metodológicos propostos por Davýdov para o ensino de Matemática. $O$ objeto de estudo consiste no movimento conceitual impresso na proposição davydoviana para o ensino do conceito de multiplicação.

Vasily Vasilyevich Davýdov nasceu em Moscou, Rússia, no ano de 1930, e faleceu em 1998, aos 68 anos de idade. O objetivo central de suas pesquisas era desenvolver uma teoria de ensino voltada para o desenvolvimento do pensamento teórico dos estudantes: trata-se da Teoria do Ensino Desenvolvimental. Suas investigações foram fundamentadas na Teoria Histórico-Cultural, fundada por Vigostki e desenvolvida por Luria, Leontiev, Galperin, Elkonin, Zaporozhets, entre outros.

Davýdov (ДАВЫДОВ) e os colaboradores Gorbov (ГОРБОВ), Mikulina (МИКУЛИНА) е Savieliev (САВЕЛЬЕВА) elaboraram uma proposta para o Ensino de Matemática e publicaram em livros didáticos, manuais de orientação ao professor, entre outros.

Os livros didáticos davydovianos são compostos por tarefas de estudo que, embora em sua lógica e estrutura interna não tenham correspondência direta com as que se apresentam nos livros didáticos brasileiros, têm em comum com eles o fato de servirem para orientar o processo de ensino e aprendizagem (ROSA, 2012; MADEIRA, 2012; SOUZA, 2013; ROSA; DAMAZIO; ALVES, 2013; ROSA; DAMAZIO; CRESTANI, 2014; ROSA; DAMAZIO; SILVEIRA, 2014; HOBOLD, 2014; SILVEIRA, 2015; BÚRIGO, 2015). 
Para o presente artigo selecionamos duas tarefas que expressam o movimento conceitual adotado. Elas foram extraídas da versão original do livro didático (no idioma russo) do segundo ano do Ensino Fundamental (DAVÝDOV et al., 2012) ${ }^{3}$. As tarefas estão escritas em russo, e a análise dessas foi realizada com o auxílio da professora de língua russa Elvira Kim.

No livro didático russo os conceitos de adição, subtração, problemas, multiplicação, divisão, sistema de numeração (por meio das diferentes bases binária, ternária, quartenária, decimal,...), geometria, equações, entre outros, são apresentados em uma rede de conceitos. Não há um capítulo específico para o estudo de cada conceito separadamente. Isso significa que não se estuda primeiro o conceito de adição, depois de subtração, multiplicação e assim sucessivamente. Mas, na medida em que se aprofundam as reflexões referentes a um conceito como, por exemplo, adição, apresentam-se outras necessidades para introduzir o conceito de multiplicação em interconexão com o conceito de adição.

Apresentamos a resolução das tarefas em conformidade com o manual de orientação ao professor, escrito pelos colaboradores de Davýdov (GORBOV; MIKULINA; SAVIELIEV, 2009) em um livro à parte, sob a forma de relato de experiência.

Nosso objetivo de pesquisa consistiu em analisar o movimento conceitual apresentado na proposição davydoviana para o ensino de multiplicação. Para concretizá-lo, realizamos os seguintes procedimentos de análise do material bibliográfico: 1) Estudo do material didático referente ao segundo ano do Ensino Fundamental; 2) Seleção das tarefas particulares que expressam o movimento conceitual da multiplicação; 3) Revelação da relação essencial, universal do conceito de multiplicação; 4) Reprodução do sistema conceitual no qual a multiplicação se insere; 4) Estudo dos fundamentos teórico-metodológicos; 5) Revelação do movimento de redução do concreto ao abstrato e posterior ascensão do abstrato ao concreto.

No primeiro contato com a versão original do material didático davydoviano, detectamos algumas tarefas que indicavam a existência de sistematização da multiplicação nos livros do segundo e terceiro anos do Ensino Fundamental ${ }^{4}$, no sistema de ensino russo. 
A análise possibilitou revelar que o ensino da multiplicação, na proposição davydoviana, é desenvolvido a partir da relação entre grandezas discretas e contínuas, na inter-relação das significações aritméticas, algébricas e geométricas, por meio de microciclos conceituais orientados do concreto ao abstrato, e deste ao concreto novamente.

Concreto e abstrato estão em constante movimento. Por exemplo, o concreto, em determinado momento do processo de cognição, transforma-se em abstrato e vice-versa. Essa transformação é marcada por um processo de redução-ascensão, e apresenta-se como estágio de superação em relação ao inicial.

De acordo com llienkov (2006, p. 152, tradução nossa) $)^{5}$ o concreto é a

[...] integridade de uma coisa, de um fenômeno, na multiplicidade de suas propriedades e determinações, na interação de todos seus aspectos e partes. Toda coisa possui numerosas facetas e partes e existe somente como integridade na diversidade de suas manifestações, diversidade em que todos os seus elementos são concatenados entre si e se condicionam reciprocamente.

O concreto é, "para o pensamento, um processo de síntese, um resultado, e não um ponto de partida, apesar de ser o verdadeiro ponto de partida e, portanto, igualmente o ponto de partida da observação imediata e da representação" (MARX, 2003, p. 248).

O concreto do momento de partida e o concreto do momento de chegada apresentam significados diferentes. Inicialmente, o real concreto "surge para o homem como o sensorialmente dado. Em suas formas especiais de contemplação e representação, a atividade sensória é capaz de captar a integridade do objeto e a existência nele das conexões que conduzem para a generalidade"(DAVÝDOV, 1982, p. 331, tradução nossa) ${ }^{6}$. Nas diferentes etapas do conhecimento, de acordo com llienkov (2006, p. 159, tradução nossa) ${ }^{7}$,

[...] a realidade concreta se reflete de maneira distinta. Nada sabíamos dela sem que primeiramente não nos seja dada, na contemplação sensorial, em nossas sensações. O concreto se oferece diretamente para a contemplação sensorial; neste sentido o definimos como o perceptível e visível diretamente. A cognição somente pode iniciar-se partindo desse concreto sensorial, deste dado de maneira imediata e visível, tangível. 
O concreto e o abstrato, de acordo com Rosental (1962, p. 324), são de grande importância para a compreensão da "essência do conhecimento". A essência é constituída na elevação do fenômeno para a lei. Um dos aspectos desse movimento "é a relação entre o abstrato e o concreto [...]", o caminho que leva do mundo objetivo para a abstração (ILIENKOV, 2006, p. 151, tradução nossa) $)^{8}$.

A abstração inicial, substancial, expressa a essência do objeto concreto. A essência é a conexão interna, que garante todas as especificidades particulares do objeto.

[...] Trata-se de conexões objetivas, as que em sua dissociação e manifestação asseguram a unidade dos aspectos do todo, isto é, dão ao objeto um caráter concreto. Neste sentido, a essência é a determinação universal do objeto. Por isso a abstração geneticamente inicial, substancial, expressa a essência do objeto concreto. A abstração substancial, pela qual quaisquer objetos se reduzem a sua forma universal (DAVÍDOV, 1988, p. 147, tradução nossa) $)^{9}$.

O universal, como essência, aparece em forma de lei. O conhecimento não passa, imediatamente, "do sensorial-concreto ao concreto pensado. Esse caminho, como todos os outros, é complexo e contraditório. Para atingir a concreticidade autêntica, o conhecimento perde temporariamente a concreticidade em geral e passa ao seu próprio oposto: ao abstrato" (KOPNIN, 1978, p. 158).

Por outro lado, "o concreto, no conhecimento, é um todo reproduzido no pensar; [...]" (ILIENKOV, 2006, p. 153, tradução nossa) ${ }^{10}$. O concreto, no pensamento,

é o conhecimento mais profundo e substancial dos fenômenos da realidade, pois reflete com o seu conteúdo não as definibilidades exteriores do objeto em sua relação imediata, acessível à contemplação viva, mas diversos aspectos substanciais, conexões, relações em sua vinculação interna necessária. Abstraç̃es isoladas elevam o nosso conhecimento da apreensão geral do empírico ao universal, enquanto o concreto no pensamento fundamenta a conexão do singular com o universal, fornece não uma simples unidade de aspectos diversos, mas a identidade dos contrários (KOPNIN, 1978, p. 162, grifo do autor). 
A abstração inicial reflete "a essência, a lei dos fenômenos, de maneira abstrata, em seu aspecto puro" (ILIENKOV, 2006, p. 169, tradução nossa) ${ }^{11}$. Desse modo, no processo de ensino, a orientação davydoviana é para a revelação da base única que gera os conceitos em seu aspecto puro, isto é, à sua essência (DAVÍDOV, 1988). Tanto o ponto de partida quanto de chegada, na proposição davydoviana, são as grandezas. Grandezas são as propriedades dos objetos que permitem determinar seu tamanho: maior, menor, igual; enfim, sua medida. Para cada conceito há uma relação diferente entre as grandezas que lhe dá origem. Assim, no início do processo de ensino e aprendizagem de cada conceito, Davýdov propõe que sejam revelados os elementos que compõem tal relação e como estes se interconectam. $\mathrm{Na}$ sequência, essa relação é abstraída do material sensorialmente dado e, posteriormente, possibilita reprodução do concreto.

$\mathrm{Na}$ especificidade do conceito de multiplicação, os elementos que constituem a relação universal do conceito surgem a partir da necessidade de se determinar um valor consideravelmente maior que a unidade de medida disponível. Nos casos em que a utilização de unidade de medida pequena (básica) é considerada trabalhosa, demorada, sugere-se a reprodução de outra, maior que a inicial, uma unidade de medida intermediária. Para exemplificar a objetivação desse movimento na proposição davydoviana, selecionamos, para o presente artigo, duas tarefas, conforme apresentamos na sequência. Porém, é necessário ressaltar que se trata de um recorte, pois antes são propostas várias tarefas. Portanto, a primeira tarefa aqui apresentada não coincide com a primeira do material didático. A seleção realizada ocorreu em função do objeto de estudo: movimento conceitual orientado do concreto ao abstrato e deste ao concreto ${ }^{12}$.

\section{TAREFAS DAVYDOVIANAS}

Tarefa 1: A primeira tarefa selecionada sugere que os estudantes investiguem o método adotado na contagem das estrelas, apresentadas na ilustração 1, Complete o esquema (DAVÝDOV et al., 2012). 
Ilustração 1 - Tarefa 1, concreto ponto de partida

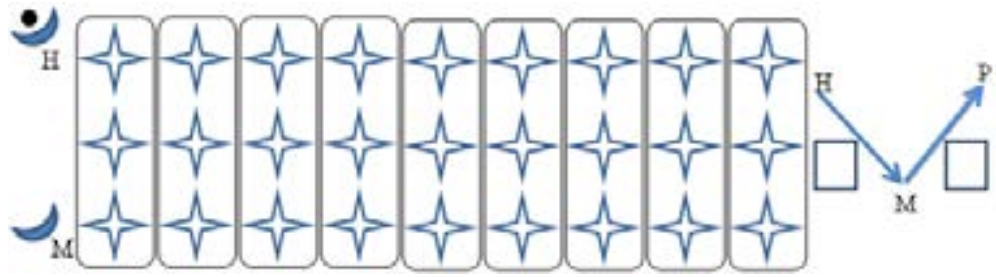

Fonte: Elaboração nossa com base na proposição davydoviana (DAVÝDOV et al., 2012, p. 58).

O esquema de setas (llustração 1) indica o valor abstrato da unidade de medida básica $(H)$, unidade de medida intermediária $(M)$, e o total de estrelas $\mathrm{P}$ (unidades básicas). $\mathrm{O}$ concreto ponto de partida da tarefa incide na quantidade de estrelas sensorialmente dada. $O$ desenvolvimento da tarefa requer a identificação dos elementos que constituem a relação abstrata do conceito de multiplicação, e como eles se interconectam. De acordo com a ilustração 1, a unidade de medida básica é uma estrela. Porém, a contagem não foi realizada de estrela em estrela, o que tornaria o processo demorado, mas a partir da unidade de medida intermediária, composta pela quantidade de estrelas apresentadas em cada coluna (3). Como são nove colunas, a unidade de medida intermediária repete-se por nove vezes. $A$ interpretação deve ser registrada no esquema de setas, conforme ilustração 2 (GORBOV; MIKULINA; SAVIELIEV, 2009).

Ilustração 2 - Tarefa 1, redução do concreto ao abstrato (no esquema)
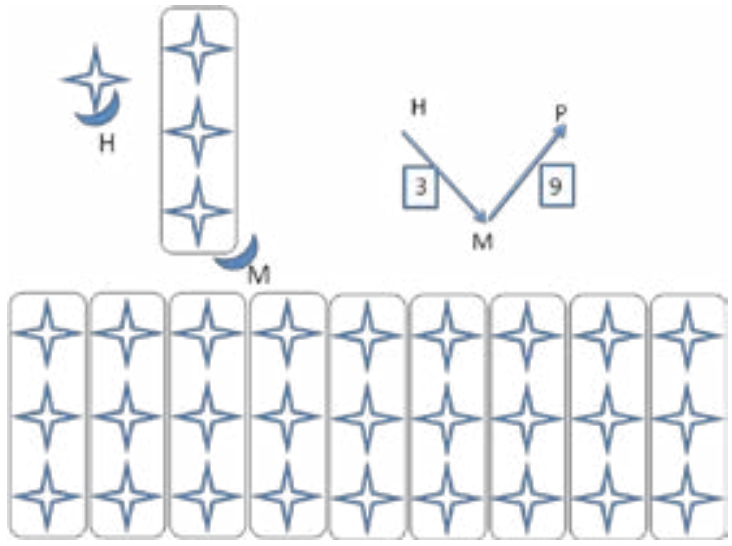

Fonte: Elaboração nossa com base na proposição davydoviana (DAVÝDOV et al., 2012). 
O foco da análise incide no procedimento de contagem e não apenas no produto. Por meio da reflexão do processo é possível identificar os elementos que compõem a relação geneticamente inicial do conceito de multiplicação: unidade de medida básica, unidade de medida intermediária e quantidade de vezes que ambas se repetem. Na proposição davydoviana são apresentadas várias tarefas para o ensino do conceito de multiplicação com diferentes grandezas (volumes, massa, área...), cujo desenvolvimento requer a reflexão sobre os elementos. A relação entre eles é analisada, inicialmente, no plano objetal, mas não se limita a esse. Por meio de um processo de abstração, os dados são representados no esquema de setas, onde não importa a grandeza considerada, nem os objetos em medição ou contagem. A representação da relação, no esquema, possibilita a "redução das diferenças existentes dentro do todo, à base única que as gera" (DAVÍDOV, 1988, p. 147, tradução nossa) ${ }^{13}$ : unidades de medida básica e intermediária, e o total de ambas. No esquema está representado o caráter interno da conexão geradora do conceito de multiplicação em seu teor universal, uma vez que,

Perante o homem, o concreto real aparece, no começo, como o que é dado sensorialmente. A atividade sensorial em suas formas peculiares de contemplação e representação é capaz de captar a totalidade (integridade) do objeto, a presença, nele, de conexões que no processo de conhecimento conduzem à universalidade. Mas a contemplação e a representação não podem estabelecer o caráter interno destas conexões (DAVÍDOV, 1988, p. 141-142, tradução nossa) $)^{14}$.

Nesse sentido, "ensinar uma atividade prática supõe dirigir a atenção não só à parte externa, à execução prática, mas também e, fundamentalmente, à parte interior, intelectual" (NÚÑEZ; OLIVEIRA, 2013, p. 300).

Porém, não se trata de uma relação direta entre a execução prática e mental. O movimento do plano externo ao interno é mediado por um sistema de símbolos (esquema de setas) constituído, no caso da tarefa em análise, pelas significações algébricas (letras $\mathrm{H}, \mathrm{Me}$ e ), geométricas (setas) e aritméticas (os números 3 e 9).

Para Toom (2001, p. 11), a escola deveria ensinar álgebra e geometria, pois as "duas disciplinas são fundamentais, são bastante ricas de conteúdo 
e têm problemas que podem entusiasmar um cientista futuro". Essa relação entre álgebra e geometria é constantemente considerada na proposição davydoviana desde o primeiro ano escolar, diferentemente do que ocorre no sistema educacional brasileiro, no qual ainda predomina a sequência linear e fragmentada onde, primeiro, ensina-se a aritmética para depois geometria e álgebra. A última geralmente é lecionada nos anos finais da segunda fase do Ensino Fundamental. O que é lamentável, pois, de acordo com Vigotski (2000), a álgebra contribui para elevar o desenvolvimento do pensamento matemático da criança ao plano abstrato. Para se atingir a concreticidade autêntica, é necessário passar pelo abstrato (KOPNIN, 1978). E o conteúdo deste, na proposição davydoviana, é a relação geneticamente inicial que dá origem ao concreto, que atua "como base de todas as manifestações do concreto" (DAVÍDOV, 1988, p. 145, tradução nossa) ${ }^{15}$, conforme exemplificamos com a tarefa 2.

Tarefa 2: Construa as imagens a partir das informações apresentadas no esquema (llustração 3), de acordo com os valores previstos na sentença (DAVÝDOV et al., 2012).

Ilustração 3 - Tarefa 2, reprodução do concreto a partir do abstrato

1) $3 \times 5$

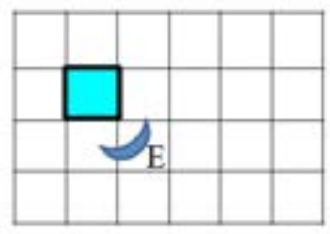

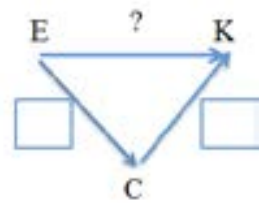

C

Fonte: Elaboração nossa com base na proposição davydoviana (DAVÝDOV et al., 2012, p. 64).

Davýdov e colaboradores orientam que o professor explique que as imagens e os registros nos esquemas estavam prontos, mas alguém as apagou. Ficou registrada apenas a expressão $3 \times 5$, e o esquema com a indicação das unidades E, C e K (Ilustração 3). A orientação é que a realização da tarefa seja iniciada pelo registro no esquema abstrato e, posteriormente, a representação objetal, conforme a ilustração 4 (GORBOV; MIKULINA; SAVIELIEV, 2009). 
Ilustração 4 - Tarefa 2, construção da unidade de medida intermediária

1) $3 \times 5$

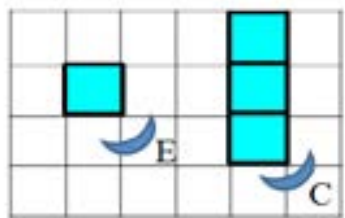

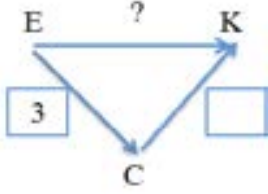

C

Fonte: Elaboração nossa com base na proposição davydoviana (DAVÝDOV et al., 2012).

Na sentença ( $3 \times 5)$, o primeiro número (3) representa a unidade de medida intermediária, composta por três (3) unidades de medidas básicas; e o segundo número, cinco (5), a quantidade de vezes que esta se repete. Após o registro do segundo termo da sentença no esquema (Ilustração 5), procede-se a construção da superfície com área $\mathrm{K}(3 \times 5)$.

Ilustração 5 - Tarefa 2, construção do esquema e do objeto a partir da sentença dada

1) $3 \times 5$
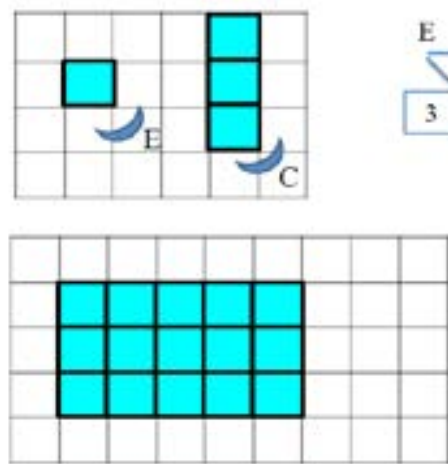

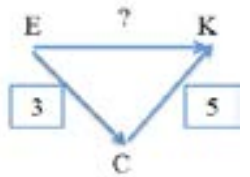

C.

Fonte: Elaboração nossa com base na proposição davydoviana (DAVÝDOV et al., 2012).

Falta, ainda, determinar o total de unidades básicas na figura construída (com medida K). Para tanto, o professor propõe que uma criança conte de unidade em unidade $(1,2,3, \ldots, 15)$, outra utilize a calculadora, e as demais realizem o cálculo com auxílio da reta numérica (Ilustração 6). A conclusão é que o resultado foi o mesmo nos três procedimentos utilizados (contagem um-a-um, calculadora e reta numérica): 3 x $5=15$ unidades básicas. Em seguida, o ponto de interrogação, no esquema, é substituído pelo resultado (GORBOV; MIKULINA; SAVIELIEV, 2009). 
Ilustração 6 - Tarefa 2, cálculo do total de unidades básicas e registro no esquema

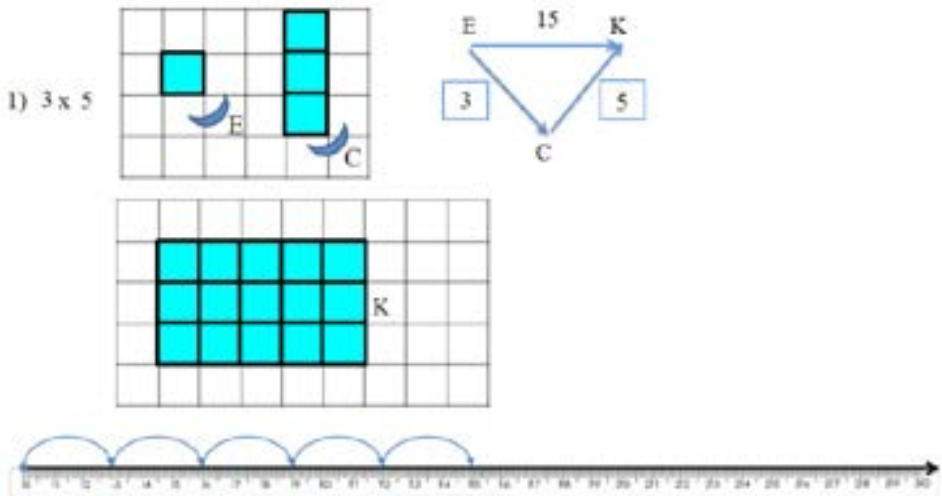

Fonte: Elaboração nossa com base na proposição davydoviana (DAVÝDOV et al., 2012).

Desse modo, a tarefa, que foi iniciada a partir da abstração (esquema), ascendeu ao concreto (construção da superfície de área K). Ela foi pensada com base na relação abstrata $(3 \times 5)$. Trata-se do concreto pensado, ponto de chegada, mas que, na mesma tarefa, constituiu-se em ponto de partida para a introdução de outra abstração, a reta numérica. Portanto, não se trata de uma sequência linear orientada do concreto ao abstrato e deste ao concreto novamente. É um movimento de microciclos que ocorrem, inclusive, no interior de uma mesma tarefa, dialeticamente.

A superfície com medida $\mathrm{K}$ é produto da cabeça pensante, é a abstração encarnada. O concreto, no conhecimento, é um todo reproduzido no pensar; [...] "é a realidade apreendida em carne e osso" (ILIENKOV, 2006, p. 153, tradução nossa) ${ }^{16}$. Por isto não coincide com as relações entre grandezas que constituíram o ponto de partida.

O caminho de nosso conhecimento desde o concreto-sensível através do abstrato para o concreto, reproduzido sobre a base do conhecimento da essência dos fenômenos, expressa a lei dialética da negação da negação no desenvolvimento do saber humano. $O$ abstrato é a negação do concreto-sensível, e o concreto, como síntese de inúmeras abstrações, é a negação do abstrato. Mas isto não significa uma simples volta para o concreto, que servia como ponto de partida, mas para o concreto elevado a um nível mais 
alto de desenvolvimento, em que o objeto é captado de modo profundo e multilateral (KOPNIN, 1958, p. 315, tradução nossa) ${ }^{17}$.

Ao final da tarefa em análise, Davýdov e colaboradores propõem que os estudantes determinem o valor aritmético da medida $\mathrm{K}$ por meio da contagem um-a-um, calculadora e reta numérica, ou seja, por meio do conhecimento concreto:

Se [...] o fenômeno ou objeto é tomado em unidade com o todo, se é examinado na sua relação com outras manifestações, com sua essência, com a origem universal (lei), trata-se de um conhecimento concreto, mesmo que seja expresso com a ajuda dos signos e símbolos mais "abstratos" e"convencionais" (DAVÍDOV, 1988, p. 150-151, grifo do autor) ${ }^{18}$.

Na reta numérica, os elementos que compõem a relação universal do conceito de multiplicação estão representados. Cada unidade de medida intermediária é representada por um arco. A quantidade de arcos refere-se ao número de vezes que a unidade de medida intermediária se repete. Esses, por sua vez, são constituídos por três unidades básicas. O ponto de chegada do último arco coincide com a quantidade de unidades básicas. Trata-se da relação universal, essencial do conceito de multiplicação, revelada na ação objetal inicial com as grandezas, e objetivada na reta numérica enquanto concreto ponto de chegada. Este, por sua vez, se constitui em ponto de partida para o desenvolvimento de outras tarefas, inclusive para a sistematização da tabuada, conforme a ilustração 7 .

llustração 7 - Tabuada do número três no contexto da reta numérica

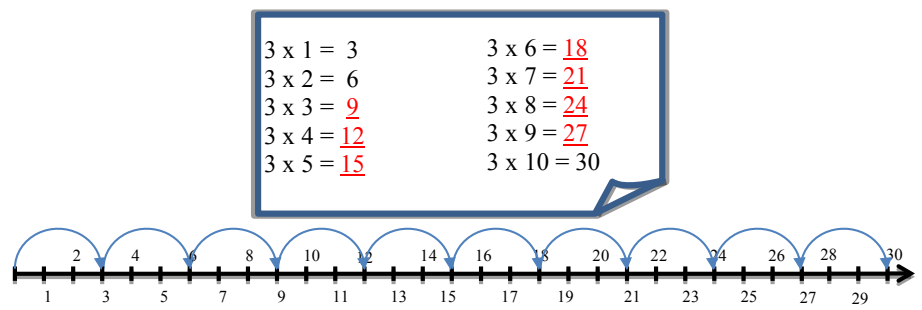

Fonte: Elaboração nossa com base na proposição davydoviana (DAVÝDOV et al., 2012).

Assim, culmina-se o processo de reprodução do concreto, no pensamento, por meio de abstrações. Vale salientar que, 
Embora os processos redução e ascensão se encontrem em unidade, "o processo fundamental é de ascensão, que expressa a natureza do pensamento teórico [...] a "redução" aparece apenas como momento subordinado, como meio para o alcance desta finalidade (DAVÍDOV, 1988, p. 148, grifo do autor, tradução nossa) $)^{19}$.

Essa é a razão da necessidade de relações reais entre grandezas como ponto de partida. Pois, como questiona Kopnin (1958, p. 304, tradução nossa) "20 "se o conhecimento sensível não nos fornecer certo conhecimento do universal, de onde poderiamos extrair o pensamento, cuja fonte é a imagem sensível?". No entanto, conforme refletimos, o foco da análise não incide em qualquer característica dos objetos, mas nas suas grandezas e como estas se relacionam a partir da percepção sensorial.

[...] no estágio da percepção sensorial da realidade, o conhecimento recebe os dados, sem esse material não se pode avançar nenhum passo. No estágio do pensar abstrato, se busca o que constitui a base, a unidade da diversidade. No estágio da reprodução mental do concreto, o círculo em certo modo se encerra no ponto de partida, porém sobre uma nova base: a diversidade se nos apresenta já não como um conjunto caótico de aspectos e relações, mas como uma unidade "organizada", subordinada a determinadas leis. O concreto, mentalmente reproduzido aparece já, não em forma de soma de diversos dados, observações, fatos, proposições separadas, etc., mas como um saber sobre fenômenos iluminados por uma única ideia (ILIENKOV, 2006, p. 160 , grifo do autor, tradução nossa) ${ }^{21}$.

A única ideia é o universal que, na especificidade do conceito de multiplicação, conforme mencionamos, é constituída pela relação interna entre as unidades de medida básica e intermediária e o total das mesmas. A relação constitui o ponto de partida e de chegada da proposição davydoviana, em um movimento orientado do concreto sensorial ao concreto pensado, mediado por abstrações.

PROPOSIÇÃO DAVYDOVIANA: PONTO DE PARTIDA E DE CHEGADA PARA REPENSAR A EDUCAÇÃo MATEMÁTICA ESCOLAR BRASILEIRA

Atualmente, muito se fala, em nosso país, sobre desenvolvimento científico e tecnológico, inovação e qualidade de vida. No entanto, atualmen- 
te, o predomínio na educação brasileira incide no ensino dos conceitos em seu teor empírico (ROSA, 2012; HOBOLD, 2014). Diante disto surge o seguinte questionamento: como pensar o desenvolvimento científico e tecnológico à mercê dos conhecimentos científicos, uma vez que são a base, o alicerce sobre o qual o desenvolvimento científico e tecnológico é desencadeado? A ciência e a tecnologia requerem a apropriação de conhecimentos, pelos sujeitos que as desenvolvem, em seu nível mais atual de desenvolvimento. Além disso, nos dias de hoje, quem não tem conhecimento fica à margem da sociedade. Portanto, falar em qualidade de vida requer, também, inclusão social, e ela passa pelo acesso aos conhecimentos científicos.

O ponto de chegada (finalidade) da proposição davydoviana incide na formação do pensamento teórico a partir da aprendizagem dos conceitos científicos por parte dos estudantes. Nessa direção, acreditamos que a proposição davydoviana pode contribuir para repensar a Educação Matemática brasileira. O movimento conceitual da multiplicação, apresentado no decorrer do artigo, é apenas uma singularidade da referida proposição que expressa sua universalidade. Contudo, sua concretização no ensino requer a síntese de múltiplas abstrações referentes aos diversos conceitos que conformam o sistema conceitual matemático constituinte do currículo escolar. Para tanto, faz-se necessária a ampliação de estudos sobre a proposição, os limites dos conteúdos e métodos vigentes em nosso país, a formação inicial e continuada de professores, melhores condições de trabalho, entre muitas outras ações.

Artigo recebido em: 29/06/2015 Aprovado para publicação em: 28/11/2015

\section{MOVEMENT BETWEEN ABSTRACT AND CONCRETE PROPOSED BY DAVYDOV TO} TEACH MULTIPLICATION

ABSTRACT: The bibliographic research was developed in the Mathematics Education context, based on the assumptions of the Cultural Historical Theory. The focus is on Davýdov's work. This author thought the objectification of fundamentals of the theory previously mentioned on teaching, and formulated the Developmental Teaching Theory. This proposition was published in articles and books, and also systematized 
through textbooks, teacher guiding books and experience report. In this article, we analyzed Davýdov's proposition for teaching the concept of multiplication. The results indicate that Davýdov's proposition contemplates the inter relationship of arithmetic, algebraic and geometric significations, through micro cycles oriented in a conceptual movement of reduction from the concrete to the abstract, and the ascension from abstract to the concrete.

KEYWORDS: Developmental Teaching Theory. Davýdov. School Mathematics Education. Multiplication.

\section{MOVIMIENTO ENTRE ABSTRACTO Y CONCRETO EN LA PROPOSICIÓN DE DAVÝDOV PARA LA ENSEÑANZA DE MULTIPLICACIÓN}

RESUMEN: La investigación, de naturaleza bibliográfica, fue desarrollada en el contexto de la Educación Matemática, con base en los presupuestos de la Teoría Histórico-Cultural. El foco es para la obra de Davýdov. Este autor pensó la objetivación de los fundamentos de la mencionada teoría en la enseñanza y formuló la Teoría de la Enseñanza del Desarrollo. Esa proposición fue publicada por medio de artículos y libros, y también sistematizada en libros didácticos, manuales de orientación para el profesorado y relatos de experiencia. En este artículo analizamos la propuesta para la enseñanza del concepto de multiplicación. Los resultados indican que la propuesta de Davýdov contempla la inter-relación de las significaciones aritméticas, algébricas y geométricas por intermedio de micro ciclos orientados en un movimiento conceptual de reducción que va de lo concreto a lo abstracto y de ascensión que va de lo abstracto a lo concreto.

Palabras-Clave: Teoría de la Enseñanza del Desarrollo. Davýdov. Educación Matemática Escolar. Multiplicación.

\section{NOTAS}

1) [...] "Sino que es una ley universal del desarrollo del conocimento humano."

2) No decorrer do texto utilizaremos a grafia Davýdov. Porém, quando se tratar de referência a alguma obra, utilizaremos a grafia apresentada na mesma: Davýdov, Davídov е Давыдов.

3) Material disponível ao público brasileiro no laboratório de Educação Matemática Prof. Dr. Ademir Damazio, da Universidade do Extremo Sul Catarinense - UNESC.

4) Correspondente ao segundo e terceiro anos do Ensino Fundamental brasileiro atual. 
5) [...] es la integridad de una cosa, de un fenómeno, en la multiplicidad de sus propiedades y determinaciones, en la interacción de todos sus aspectos y partes. Toda cosa posee numerosas facetas y partes y existe solo como integridad en la diversidad de sus manifestaciones, diversidad en que todos sus elementos se hallan concatenados entre sí y se condicionan recíproca-mente.

6) “aparece ante el hombre como lo sensorial dado. En sus formas especiales de contemplación y representación la actividad sensorial es capaz de percibir la integridad del objeto y la existencia en él de conexiones que llevan a la generalidad."

7) [...] la realidad concreta se refleja de manera distinta. Nada sabríamos de ella si primeramente no nos fuera dada en la contemplación sensorial, en nuestras sensaciones. Lo concreto se ofrece directamente a la contemplación sensorial; en este sentido, lo definimos como lo perceptible y visible directamente. La cognición sólo puede iniciarse partiendo de eso concreto, de eso dado de manera inmediata y visible, tangible.

8) "es el de la relación entre lo abstracto y lo concreto [...]"

9) [...] Se trata de enlaces objetivos, los que en su desmembración y manifestación aseguran la unidad de los aspectos del todo, es decir, dan al objeto un carácter concreto. En este sentido, la esencia es la determinación universal del objeto. Por eso la abstracción genéticamente inicial, substancial, expresa la esencia de su objeto concreto. La abstracción substancial por la cual cualesquiera objetos se reducen a su forma universal.

10) "lo concreto, en el conocimiento, es un todo reproducido en el pensar; [...]"

11) “la esencia, la ley de los fenómenos, de manera abstracta, en su aspecto puro."

12) Aos interessados em conhecer outras tarefas sobre o sistema conceitual de multiplicação em Davýdov, sugerimos a leitura de Madeira (2012) e Hobold (2014).

13) "reducción de las diferencias existentes dentro del todo a la base única que las genera"

14) Ante el hombre lo concreto real aparece al comienzo como o dado sensorialmente. La actividad sensorial en sus formas peculiares de contemplación y representación es capaz de captar la integridad del objeto, la presencia, en él, de conexiones que en el proceso de conocimiento conducen a la. Pero la contemplación y la representación no pueden establecer el carácter interno de estas conexiones.

15) "como base de todas las manifestações de lo concreto"

16) [...] "es la realidad aprehendida en carne y hueso"

17) La marcha de nuestro conocimiento desde lo concreto-sensible a través de lo abstracto hacia lo concreto, reproducido sobre la base del conocimiento de la esencia de los fenómenos, expresa la ley dialéctica de la negación de la negación en el 
desarrollo del saber humano. Lo abstracto es la negación de lo concreto-sensible, y lo concreto, como síntesis de innumerables abstracciones, es la negación de lo abstracto. Pero esto no significa una simple vuelta a lo concreto, que servía de punto de partida, sino a lo concreto elevado a un nivel más alto de desarrollo, en que el objeto es captado de modo profundo y multilateral.

18) Se [...] el fenómeno o el objeto es examinado por el hombre independiente de cierto todo, como algo externamente aislado y autónomo, se tratará sólo de un conocimiento abstracto, por más detallado e visual que sea, por más "concretos", que sean los ejemplos que lo ilustren. Si, por contrario, el fenómeno u objeto es tomado en unidad con el todo, se examina en relación con sus otras manifestaciones, con su esencia, con el origen universal (ley), se tratará de un conocimiento, concreto, aunque se exprese con ayuda de los símbolos y signos más "abstractos" y "convencionales".

19) Aunque los dos procesos ("la reducción" e la ascensión”) se encuentran en unidad, lo rector es la ascensión que expresa la naturaleza del pensamiento teórico [...] la "reducción" aparece sólo como momento subordinado, como medio para alcanzar esa finalidad.

20) " si el conocimiento sensible no nos proporcionara cierto conocimiento de lo universal, ¿ de dónde lo podría extraer el pensamiento, cuya fuente es la imagen sensible?

21)_En el estadio de la percepción sensorial de la realidad, el conocimiento recibe los datos, el material sin el que no puede avanzar ni un paso. En el estadio del pensar abstracto, se busca lo que constituye la base, la unidad de la diversidad. En el estadio de la reproducción mental de lo concreto, el círculo en cierto modo se cierra en el punto de partida, pero sobre una nueva base: la diversidad se nos presenta ya no como un conjunto caótico de aspectos y relaciones, sino como una unidad "organizada", subordinada a determinadas leyes. Lo concreto mentalmente reproducido aparece ya no en forma de suma de diversos datos, observaciones, hechos, proposiciones separadas, etc., sino como un saber sobre fenómenos iluminados por una idea única.

\section{REFERÊNCIAS}

BÚRIGO, L. S. M. Necessidades emergentes na organização do ensino davydoviano para o número negativo. Dissertação (Mestrado em Educação) - Universidade do Extremo Sul Catarinense, Criciúma, 2015.

DAMAZIO, A. O desenvolvimento de conceitos matemáticos no contexto do processo extrativo do carvão. Tese (Doutorado em Educação) - Universidade Federal de Santa Catarina, Florianópolis, 2000. 
DAVÍDOV, V. V. La enseñanza escolar y el desarrollo psíquico: investigación teórica y experimental. Tradução Marta Shuare. Moscú: Progreso, 1988.

Tipos de generalización en la enseñanza. 3.ed. Habana: Pueblo y Educación, 1982.

La revolución de la educación y el desarrollo mental de los allumnos. Revista de Pedagogia, n. 403, p. 147-150, 1998.

HOBOLD, E. S. F. Proposições para o ensino da tabuada com base nas lógicas formal e dialética. Dissertação (Mestrado em Educação) - Universidade do Sul de Santa Catarina, Tubarão, 2014. Disponível em: <https://aplicacoes.unisul.br/pergamum/ pdf/108492_Ediseia.pdf>.Acesso em: 20 jan. 2015.

ILIENKOV, E. V. La ascensión de lo abstracto a lo concreto en principios de la lógica dialéctica. In: JIMÉNEZ, Alfredo Tecla. Teoría de la construcción del objeto de estudio. México: Instituto Politécnico Nacional, 2006. p. 151-200.

KOPNIN, P. V. A dialética como lógica e teoria do conhecimento. Rio de Janeiro:

Civilização Brasileira, 1978.

. Lo abstrato y lo Concreto. In: ROSENTAL, M. M.; STRAKS, G. M. (Org.). Categorias del materialismo dialectico. México: Grijalbo, 1958. p. 299-320.

MADEIRA, S. C. "Prática": Uma leitura Histórico-Crítica e proposições davydovianas para o conceito de multiplicação. Dissertação (Mestrado em Educação) - Universidade do Extremo Sul Catarinense, Criciúma, 2012.

MARX, K. Contribuição à crítica da economia política. 3. ed. São Paulo: Martins, Fontes, 2003.

NÚÑEZ, I. B.; OLIVEIRA, M. V. Ya. Galperin: a vida e a obra do criador da teoria da formação por etapas das ações mentais e dos conceitos. In: LONGAREZI, A. M.; PUENTES, R. V. (Org.). O Ensino desenvolvimental: vida, pensamento e obra dos principais representantes russos. Uberlândia: EDUFU, 2013. p. 283-313.

NÜRNBERG, J. Tabuada: significados e sentidos produzidos pelos professores das Séries Iniciais do Ensino Fundamental. Dissertação (Mestrado em Educação) - Universidade do Extremo Sul Catarinense, Criciúma, 2008.

ROSA, J. E. Proposições de Davydov para o ensino de matemática no primeiro ano escolar: inter-relações dos sistemas de significações numéricas. Tese (Doutorado em Educação) - Universidade Federal do Paraná, Curitiba, 2012.

; DAMAZIO, A.; ALVES, E. de S. B. Adição e subtração em Davydov. Boletim GEPEM / Grupo de Estudos e Pesquisas em Educação Matemática, Rio de Janeiro, n. 63, p. 61-75, jul./dez. 2013. 
; ___ _ CRESTANI, S. Os conceitos de divisão e multiplicação nas proposições de ensino elaboradas por Davydov e seus colaboradores. Educação Matemática Pesquisa (Online), v. 16, p. 167-187, 2014.

; _ _ SILVEIRA, G. M. O Sistema de Numeração nas Tarefas Propostas por Davydov e seus Colaboradores para o Ensino de Matemática. Boletim de Educação Matemática - BOLEMA, São Paulo, v. 28, n. 50, p. 1135-1154, dez. 2014.

ROSENTAL, M. M. Princípios de Logica Dialectica. Tradução Augusto Vidal Boget. Montevidéu: Pueblos Unidos, 1962.

RUBINSTEIN, S. L. O desarrollo de La psicología: principios y métodos. Habana: Pueblos y Educación, 1979.

SILVEIRA, G. M. Unidade entre lógico e histórico no movimento conceitual do sistema de numeração proposta por Davýdov e colaboradores para o ensino das operações da adição e subtração. Dissertação (Mestrado em Educação) - Universidade do Sul de Santa Catarina, Tubarão, 2015.

SOUZA, M. B. O ensino do conceito de número: objetivações nas proposições davydovianas e formalista moderna. Dissertação (Mestrado em Educação) - Universidade do Extremo Sul Catarinense, Criciúma, 2013.

TOOM, A. Ensino: o efeito dominó. Matemática Universitária, n. 30, p. 5-14, jun. 2001. VIGOTSKI, L. S. A construção do pensamento e da linguagem. São Paulo: Martins Fontes, 2000.

WIGGERS, V. Conceitos de educação e de educação infantil. Poiésis, Tubarão, Volume Especial, p. 102-120, jan./jun. 2014.

GORBOV, S. F.; MIKULINA, G.G; SAVIELIEV, O.V. Ensino de Matemática. 2 ano: livro do professor do ensino fundamental. Moscú: Vita- Press, 2009.

DAVÝDOV, V. V. etal.Matemática. 2 ano: livro didático e de exercícios do Ensino Fundamental. Moscú: Vita- Press, 2012.

JosÉLIA EuZÉBIO DA RosA é doutora em Educação pela Universidade Federal do Paraná (UFPR). Professora do Programa de Pós-Graduação em Educação da Universidade do Sul de Santa Catarina (UNISUL). Integrante de três grupos de pesquisa, o GEPAPe (Grupo de Estudos e Pesquisa Sobre Atividades Pedagógicas - USP), o GPEMAHC (Grupo de Pesquisa em Educação Matemática: uma Abordagem Histórico-Cultural - UNESC), e o TEDMAT (Teoria do Ensino Desenvolvimental na Educação Matemática - UNISUL). Nesse último, participa na qualidade coordenadora.

E-mail: joselia.rosa@unisul.br 
Ediséla Suethe Faust HOBOld é Mestre em Educação pela Universidade do Sul de Santa Catarina (UNISUL), Linha de Pesquisa Educação em Ciências. Integrante de dois grupos de pesquisa o GPEMAHC (Grupo de Pesquisa em Educação Matemática: uma Abordagem Histórico-Cultural - UNESC) e o TEDMAT (Teoria do Ensino Desenvolvimental na Educação Matemática - UNISUL). Professora de Matemática da rede estadual de Santa Catarina.

E-mail: ediseiafhobold@yahoo.com.br 
